\title{
Effect of sand content on stabilization of dredged soil - steel slag mixture
}

\author{
T. Kaneko ${ }^{\text {i) }}$ and Y. Watabe ${ }^{\text {ii) }}$
}

i) Researcher, Geotechnical Engineering Field, Port and Airport Research Institute, 3-1-1 Nagase, Yokosuka, 239-0826, Japan

ii) Director, Geotechnical Engineering Field, Port and Airport Research Institute, 3-1-1 Nagase, Yokosuka, 239-0826, Japan

\begin{abstract}
A series of unconfined compression tests and triaxial compression tests was conducted for the mixture of dredged soil and steel slag with various sand contents. Furthermore, internal structure and microfabric of the specimens were observed by X-ray CT, scanning electron microscope (SEM) and mercury intrusion porosimetry (MIP). The compressive strength increased with increase in sand content, and the failure process observed by X-ray CT varied according to sand content; however, a clear difference was not seen in the microfabric of the dredged soil - steel slag mixture by SEM and MIP even if the sand content changes.
\end{abstract}

Keywords: dredged soil, steel slag, mechanical property

\section{INTRODUCTION}

In recent years, effective utilization of dredged soil is an important issue so that the capacity of waste disposal facilities is rapidly dwindling. Mixture of dredged soil and steel slag has been studied as one of the applications of dredged soil for geomaterial, and it was found out that the mixture of dredged soil and steel slag was environmentally safe and applicable to improvement for bottom sediment if it was employed as geomaterial in marine area ${ }^{1), 2)}$. The strength of the mixture is greatly affected by the compatibility of the properties of dredged soil and steel slag, particularly the influence of sand content on stabilization is one of the key factors. It is thought that the elution of the silica ingredient from clay is necessary for stabilization of the mixture of dredged soil and steel slag. However the influence of the sand fraction has not been studied. In this study, a series of unconfined compression tests and triaxial compression tests was conducted for the mixture of dredged soil and steel slag with various sand contents. Furthermore, microfabric of the specimens were observed by X-ray CT, scanning electron microscope (SEM) and mercury intrusion porosimetry (MIP), and the transition of mechanical properties, microfabric of the specimens and failure process with the variation of sand fraction content was examined.

\section{SAMPLE AND SPECIMEN}

In this study, dredged soil $\left(\rho_{\mathrm{s}}=2.739 \mathrm{~g} / \mathrm{cm}^{3}, w_{\mathrm{L}}=\right.$ $\left.116.1 \%, w_{\mathrm{P}}=38.5 \%\right)$ from the Osaka Port navigation channel, Toyoura sand $\left(\rho_{\mathrm{s}}=2.653 \mathrm{~g} / \mathrm{cm}^{3}\right)$ and steel slag $\left(\rho_{\mathrm{s}}=3.596 \mathrm{~g} / \mathrm{cm}^{3}\right)$ were used. Their particle size

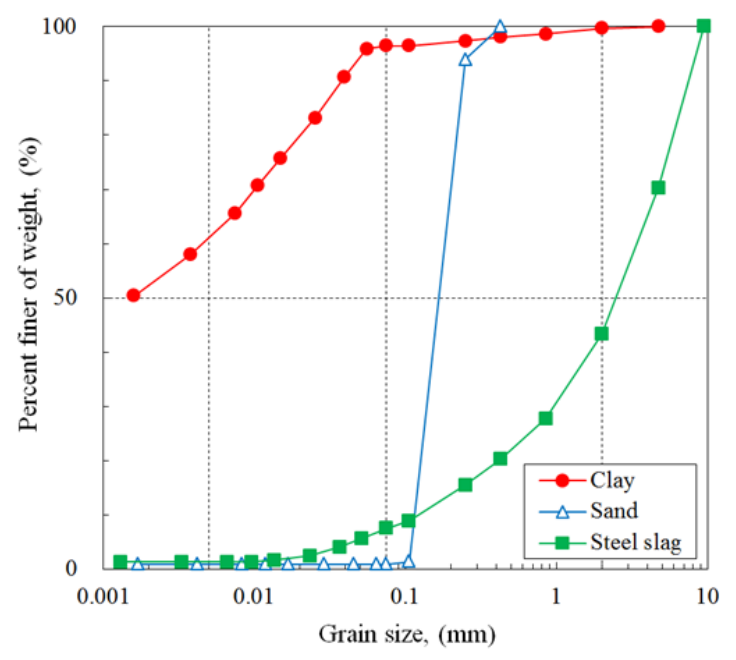

Fig.1 Particle size distribution curves

distribution curves are shown in Fig.1.

After strained through a sieve of $0.425 \mathrm{~mm}$, dredged soil was mixed with water to adjust water content 1.5 times of the liquid limit. Then, dredged soil slurry and sand were mixed by dry weight ratio as 10:0, 8:2, 6:4, 5:5, 4:6, 3:7 and 2:8 (OS0, OS20, OS40, OS50, OS60, OS70 and OS80). The steel slag of 20\% volumetric percentage for the mixture soil was added to the soil slurry and it was sufficiently mixed. The mixture was placed with tamping by 3 layers into a mold with 50 $\mathrm{mm}$ in diameter to remove air bubbles. Then, it was put in plastic containers and cured at room temperature of 20 degrees Celsius until the test. Furthermore, curing periods were 7 and 14 days. After curing, the specimens were removed from the mold, and trimmed the end face to be $100 \mathrm{~mm}$ height. 


\section{MECHANICAL PROPERTIES}

\subsection{Unconfined compression tests}

Unconfined compression tests were conducted for the specimens OS0, OS20, OS40, OS50, OS60, OS70 and OS80 at curing ages of 7 and 14 days. Furthermore, 3 specimens were prepared for each condition, and the mean values were calculated and plotted in the following figures. Fig.2 shows the relationship between the unconfined compressive strength and the sand content. The unconfined compressive strength exponentially increases with the sand content. In both the age of 7 and 14 day, but the latter is $80 \%$ larger than the former. To consider the change of the unconfined compressive strength with curing age, the strength ratio is defined as the unconfined compressive strength at 14 day divided by the unconfined compressive strength at 7 day. The relationship between the strength ratio and the sand content is plotted in Fig.3. The figure shows that the strength ratio is approximately constant at 1.6 in sand contents smaller than $60 \%$, whereas the strength ratio is increased in sand content lager than $70 \%$.

\subsection{Triaxial compression tests}

Unconsolidated undrained triaxial compression tests were conducted for specimens OS0, OS50 and OS80 at a curing age of 7 day. Furthermore, 3 specimens were prepared for each condition, and applied confining pressure of 50, 100 and $200 \mathrm{kN} / \mathrm{m}^{3}$, respectively. Fig. 4 shows the relationship between the triaxial compressive strength and the sand content. The unconfined compressive strengths at 7 day are superimposed in the figure. It is confirmed that the triaxial compressive strength increases with the sand content, as with the relationship for unconfined compressive strength. Fig.5 shows the relationship between the triaxial compressive strength and the confining pressure. The triaxial compressive strength is approximately constant at sand contents of 0 and $50 \%$, whereas the triaxial compressive strength is increased with confining pressure at a sand content of $80 \%$.

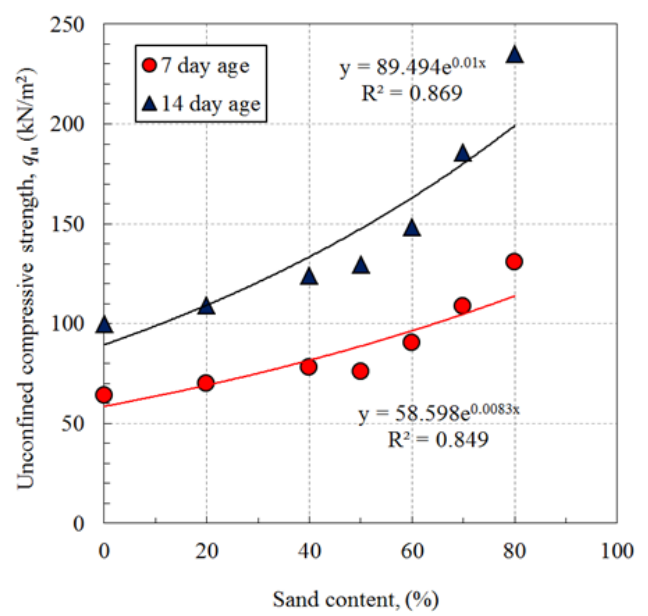

Fig.2 Relationship between unconfined compressive strength and sand content

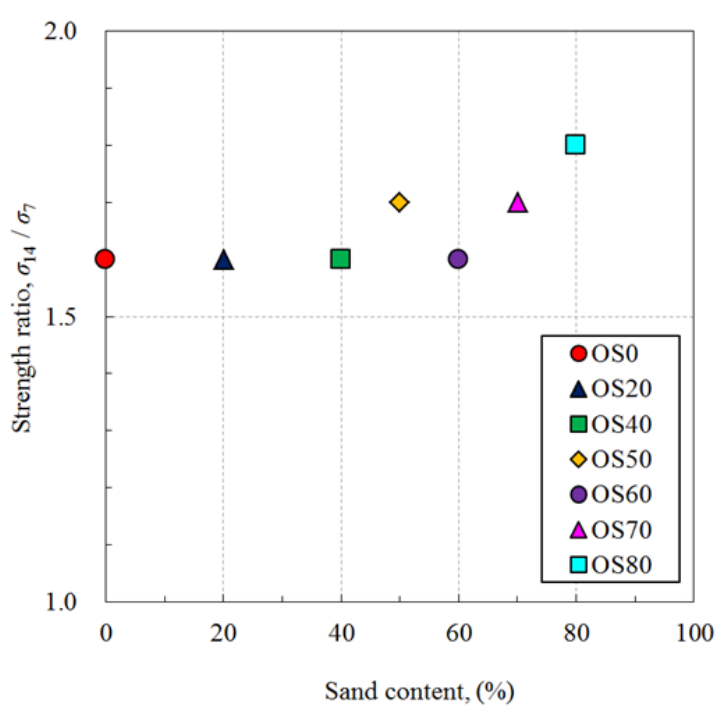

Fig.3 Relationship between strength ratio and sand content

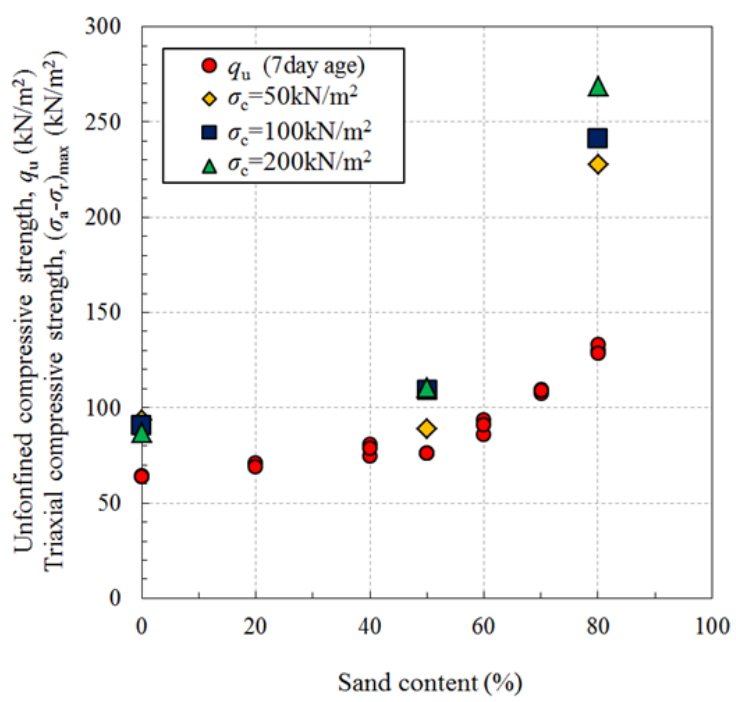

Fig.4 Relationship between compressive strength and sand content

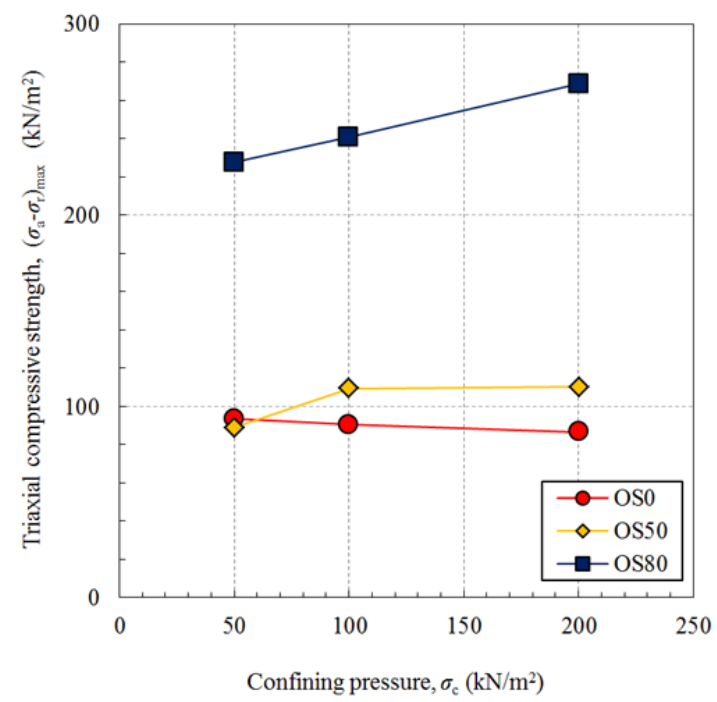

Fig.5 Relationship between triaxial compressive strength and confining pressure 


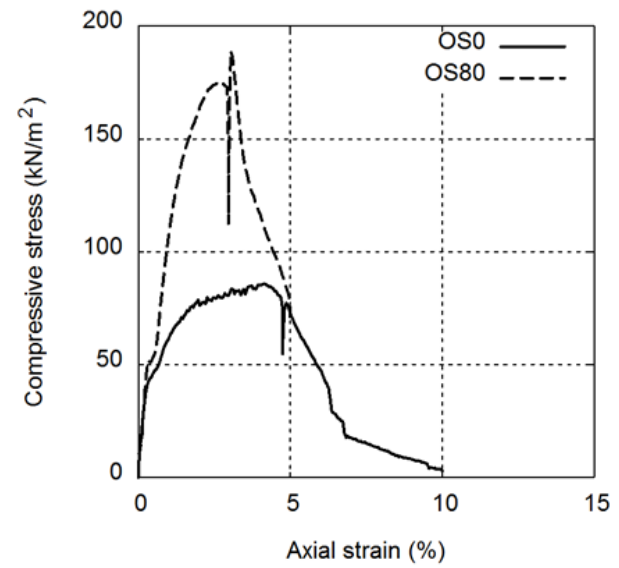

Fig.6 Relationship between unconfined compressive strength and axial strain

\section{OBSERVATION OF SPECIMEN BY X-RAY CT}

The specimens OS0 and OS80 at curing age of 7 days were observed by micro focus X-ray CT system. Because this system can set up a soil-testing apparatus inside $^{3)}$, CT image observation can be conducted for the test specimen while performing compression tests.

Unconfined compression tests were conducted for the specimens to obtain the CT images when axial load reached the peak. The relationship between the compressive stress and axial strain is shown in Fig.6. A significant decrease in stress near the peak caused by relaxation during image obtainment.

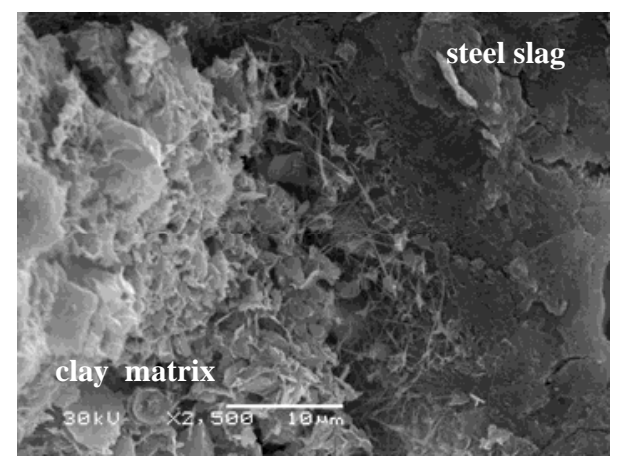

(a) Interface between steel slag and clay matrix Fig.8 SEM image for OS0

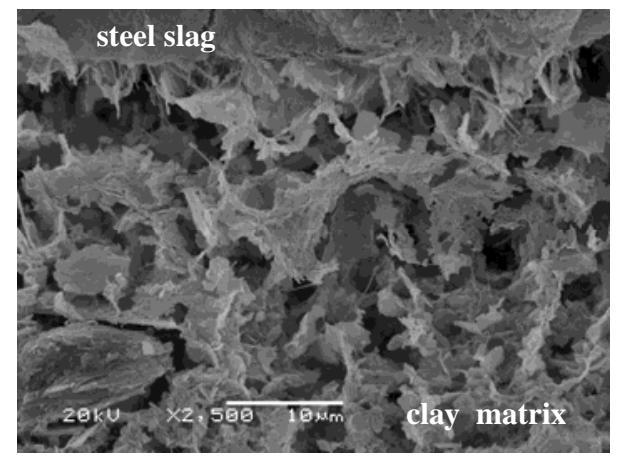

(a) Interface between steel slag and clay matrix Fig.9 SEM image for OS80

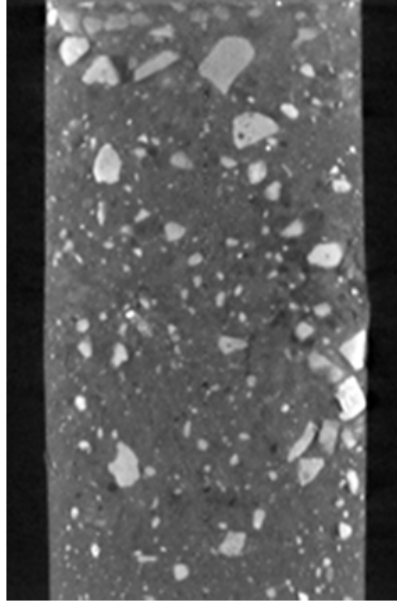

(a) OS0

Fig.7 X-ray CT image

Fig.7(a) shows that a crack occurred from an interface between steel slag and clay matrix at the right-center of specimen OS0 without sand. On the other hand, in Fig.7(b) a crack occurred from the upper left to the lower right of specimen OS80. It seems that the specimen OS80 with much sand content failed like general soil materials, because the rigidity and the strength of the specimen were relatively uniform, however the specimen OS0 without sand progressively failed from an interface between steel slag and clay matrix because the specimen was not uniform.

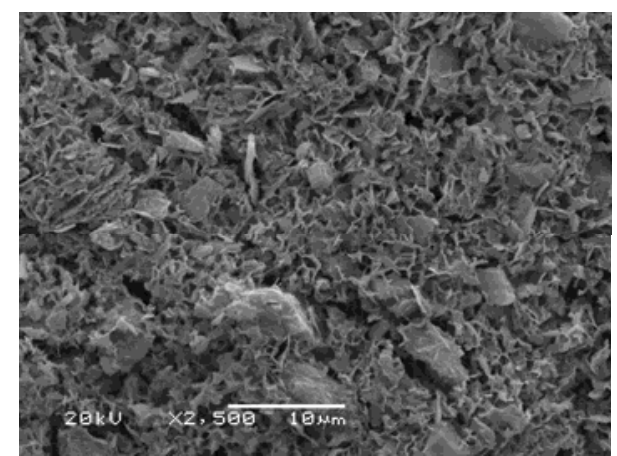

(b) A part of clay matrix

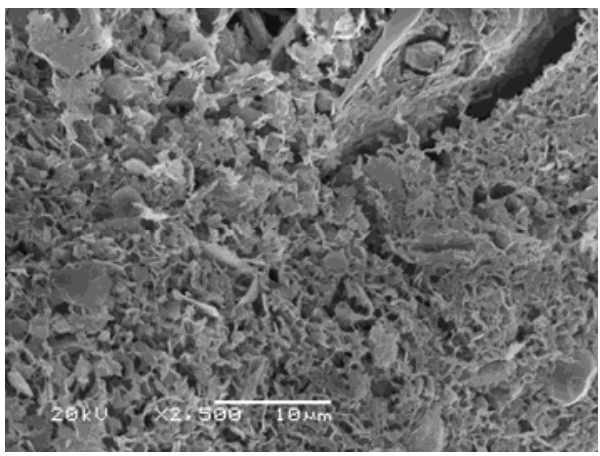

(b) A Part of clay matrix with sand particle 


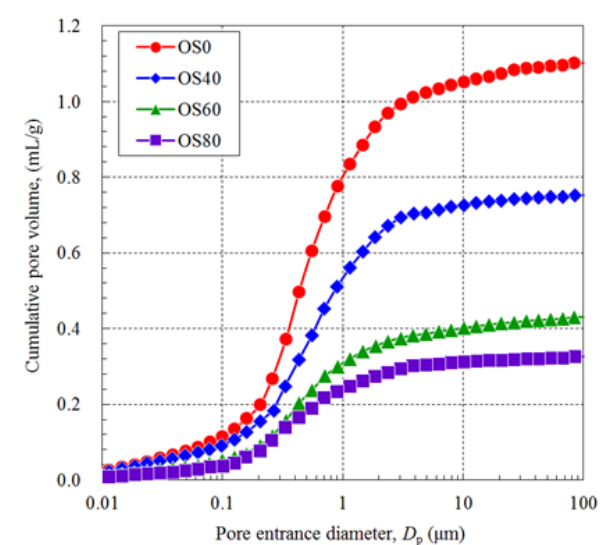

Fig.10 Relationship between cumulative pore volume and pore entrance diameter

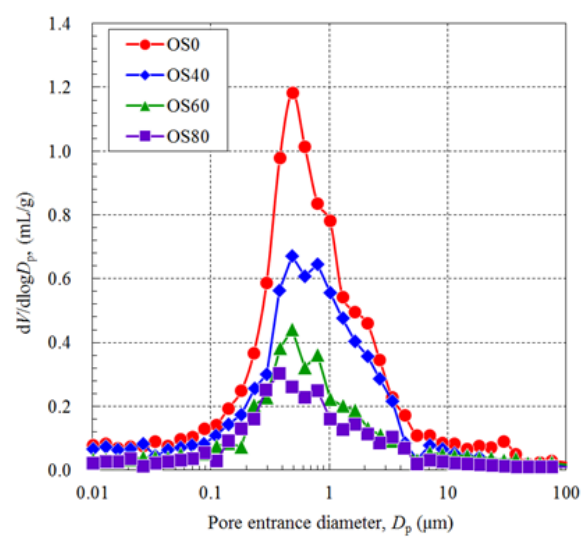

Fig.11 Frequency of pore entrance diameter

\section{OBSERVATION AND QUANTIFICATION OF MICROFABRIC}

Microfabric of the specimens was observed by scanning electron microscope (SEM) and mercury intrusion porosimetry (MIP).

Observed microfabric of the specimens OS0 and OS80 at curing age of 7 days are shown in Figs.8 and 9, respectively; (a) an interface between steel slag particle and clay matrix and (b) a part of clay matrix. From Fig.8(a) and Fig.9(a), the needle-like hydrate produced on the boundary of steel slag and clay matrix are seen for both the specimens of OS0 and OS80. On the other hand, microfabric does not have significant difference in the part of clay matrix even if the sand content changes.

The pore size distribution of the specimens OS0, OS40, OS60 and OS80 at curing age of 7 days were measured by MIP. Relationships between cumulative pore volume and pore entrance diameter are shown in Fig.10. The pore volume decreased with increase of the sand content. This corresponds to that some parts of clay matrix including voids were replaced by sand particles with increase of sand content. On the other hand, the most frequent pore diameter at the maximum $\mathrm{d} V / \mathrm{d} \log D_{\mathrm{p}}$ does not change in Fig.11. This fact indicates that the microfabric of the clay matrix was not affected by sand particles. Therefore, a clear difference does not confirm in the microfabric of the dredged soil - steel slag mixture even if the sand content changes.

\section{CONCLUSIONS}

In this study, transition of mechanical property, internal structure of specimen and failure process with the variation of sand fraction content was examined. The main findings obtained from the test results are as follows.

1. The unconfined compressive strength exponentially increased with the sand content

2. The strength ratio was approximately constant up to a sand content of $60 \%$, whereas the strength ratio increased with sand content when it is higher than that.

3. The triaxial compressive strength was approximately constant at sand content less than $50 \%$, whereas the triaxial compressive strength increased with confining pressure at sand content of $80 \%$.

4. The specimen with high sand content failed like general soil materials because the rigidity and the strength of the specimen were relatively uniform; however, the specimen without sand progressively failed from an interface between steel slag and clay matrix because the specimen was not uniform.

5. A clear difference was not seen in the microfabric of the dredged soil - steel slag mixture by SEM and MIP even if the sand content changes.

\section{ACKNOWLEDGEMENTS}

The authors wish to express their thanks to the people involved from Kobe Research and Engineering office for Port and Airport, Kinki Regional Development Bureau, Ministry of Land, Infrastructure Transport and Tourism, and Nippon Steel and Sumitomo Metal Corporation for their support. The authors wish to express their thanks to Dr. T. Mizutani and Mr. T. Shinonaga of the Port and Airport Research Institute for Photography of the CT image.

\section{REFERENCES}

1) Nippon Steel Corporation, JFE Steel Corporation (2010): Technology to Improve Coastal Area Environments Using Converter Steel Slag Products, Verification Results of Water Environment Improvement Technologies for Enclosed Coastal Seas Field, Environmental Technology Verification Program, Ministry of the Environment. (in Japanese).

2) The Japan Iron and Steel Federation (2008): Mixed Improved Method of Converter Steel Slag and Dredged Soil Technical Data, Guide of Converter Steel Slag Utilizing to Sea Area Separate Volume. (in Japanese).

3) Yoshiaki Kikuchi, Takaaki Mizutani, Takeshi Nagatome, Toshiro Hata (2006): Study on Applicability of Micro-focus X-ray CT Scanner for Geomaterials, Technical note of The Port and Airport Research Institute, No.1125. (in Japanese). 